\title{
Memoria y resistencia en los relatos de la copla del Valle Calchaquí (Salta, Argentina) Concepciones acerca de la naturaleza
}

\section{María Cecilia Páez, ${ }^{1}$ Alejandro Martínez, ${ }^{2}$ Francisco Eduardo Riegler ${ }^{3}$ y Catalina Martínez Zabala4} \author{
(iD) https://orcid.org/oooo-0001-6405-9202 \\ Correo electrónico: ceciliapaez@gmail.com \\ 2 Facultad de Ciencias Naturales y Museo, Universidad Nacional de La Plata \\ (iD) https://orcid.org/oooo-0002-8767-5152 \\ Correo electrónico: alephmartinez@hotmail.com \\ 3 Facultad de Ciencias Naturales y Museo, Universidad Nacional de La Plata \\ (iD) https://orcid.org/oooo-0003-3924-6860 \\ Correo electrónico: franciscoriegler@gmail.com \\ 4 Facultad de Ciencias Naturales y Museo, Universidad Nacional de La Plata \\ (iD) https://orcid.org/0000-0002-4924-5709 \\ Correo electrónico: catammzz@gmail.com
}

1 CONICET, Museo de La Plata, Facultad de Ciencias Naturales y Museo, Universidad Nacional de La Plata
Recibido:

6 de septiembre de 2019 Aceptado:

28 de agosto de 2020

doi: 10.34096/runa.v42i1.7965

\section{Resumen}

La etnografía en sociedades no occidentales ha puesto en tensión la concepción naturaleza-cultura, y esto le ha quitado el carácter de universalidad. En el marco de esta discusión, en este trabajo nos proponemos explorar los matices que adquiere esta relación a partir de los relatos de la copla, un tipo de narrativa que da cuenta de las maneras de significar y representar el mundo para quienes las producen y reproducen. A los fines de nuestro objetivo trabajamos a partir de un conjunto de coplas procedentes de la zona norte del Valle Calchaquí, específicamente en el departamento de Cachi (Salta) y de entrevistas semiestructuradas, obtenidas en trabajos de campo, así como de recopilaciones bibliográficas. En algunos casos, personificada, la naturaleza aparece dotada de cualidades de sujeto en la interacción con los humanos. Interpretamos estas características en asociación con las formas de ver el mundo de los pueblos indígenas que habitaron la región y que ha quedado plasmada en el registro de las piedras huanca.

\section{Palabras clave}

Cultura/Naturaleza; Copla Modernidad; Mundo andino; Ancestralidad 


\section{Memory and resistance in the stories of the copla of the Cal- chaquí Valley (Salta, Argentina) Conceptions about nature}

\begin{abstract}
Key words

Culture/Nature; Copla Modernity; Andean world; Ancestrality

Ethnography in non-Western societies has put a strain on the nature-culture conception, taking away its universal character. Within the framework of this discussion, here we propose to explore the nuances that this relationship acquires from the coplas, a type of narrative that accounts for the ways of signifying and representing the world for those who produce and reproduce them. For our purposes we work on a set of coplas from the northern zone of the Calchaquí Valley, specifically in the department of Cachi (Salta) and from semi-structured interviews, obtained in field work, as well as from bibliographical compilations. In some cases nature appears personified, endowed with the qualities of a subject in her interaction with humans. We interpret these characteristics in association with the forms of representation of the indigenous peoples that inhabited the region and which have been represented in the huanca stones.
\end{abstract}

Palavras-chave

Cultura/Natureza; Coplas; Modernidade; Mundo andino; Ancestralidade

\section{Memória e resistência nas histórias da copla do Vale Calcha- quí (Salta, Argentina). Concepções acerca da natureza}

\section{Resumo}

A etnografia em sociedades não ocidentais colocou em tensão a concepção natureza/cultura, tirando seu caráter de universalidade. No contexto desta discussão, neste artigo propomos explorar as nuances da referida relação a partir dos relatos da copla. Este tipo de narrativa é apresentado como um possível ponto de partida para identificar outras formas de significar e de representar o mundo para aqueles que as produzem e reproduzem. Para levar a cabo o nosso objetivo, trabalhamos a partir de um conjunto de coplas da região norte do Valle Calchaquí, especificamente no departamento de Cachi (Salta), de compilações bibliográficas, bem como a partir de entrevistas semiestruturadas, obtidas através do nosso trabalho de campo. Em alguns casos, personificada, a natureza aparece dotada de qualidades de sujeito na interação com os humanos. Interpretamos que essas características podem estar ligadas à forma de ver o mundo dos povos indígenas que habitaram a região e que foram plasmadas no registro das pedras huanca.

\section{Introducción}

Para pensar un concepto tan complejo y amplio como lo es el de naturaleza, es necesario revisar brevemente cómo, durante el desarrollo de la modernidad, se ha ido conformando el proceso de racionalización y, con este, la construcción de dicho concepto. Como menciona Melamed (2013), el proyecto de la modernidad viene a posicionar un punto de quiebre con el mundo antiguo $y$, a diferencia de este, se vincula con las ideas de progreso, desarrollo, racionalidad 
y universalidad, entre otras. Estas adoptan como principio fundamental el de la subjetividad, reivindicando el carácter referencial del individuo y su capacidad crítica, pues la razón es, en la modernidad, "la fuente privilegiada de conocimiento, y por ello también es instrumento de dominio: el mundo reducido a objeto" (Melamed, 2013, p. 166). Siguiendo esta línea, para Occidente, la naturaleza es resultado de un conjunto de leyes que dependen de la estructura de la razón y no de la experiencia. Estos objetos son ahora gobernados por leyes autónomas. En este sentido, la naturaleza se antepone a la razón, a la cultura. Y es en esa dicotomía donde se la separa y se la objetiviza (Descola, 2012).

Esta posición ha sido puesta en cuestión, aun dentro de la misma episteme modernista. Al respecto, Latour (2007) sostiene que lo que definimos como naturaleza y cultura no están diferenciados en el ámbito de la práctica. Señala que la modernidad crea una separación a partir de un proceso de "purificación", a la vez que niega la existencia de "híbridos" (mezcla de géneros, híbridos de naturaleza y de cultura). A partir de esto, discute nuestra condición de modernos, puesto que no hacemos más que construir híbridos, redes, relaciones entre estas dos ontologías.

En este devenir del desarrollo de la modernidad y del pensamiento científico, es también cuando la antropología comienza a dar sus primeros pasos. De acuerdo con Descola (2012), esta disciplina se abocó al estudio de la diversidad, no sin dejar de lado las ideas y las garantías de la Ilustración. Pues, a la vez que fue constituyendo su labor mediante el estudio de la "diversidad cultural", ya sea instituciones o modos de pensar, fue dándole legitimidad a esta condición dentro de la norma occidental. En este contexto, el concepto de naturaleza ha estado relegado a una función de entorno, donde esta y el sujeto constituyen entidades aislables, en una relación objeto/sujeto (Descola 2012). Cada una es definida en función de la otra; es decir, la redefinición de la cultura conlleva un reposicionamiento del concepto de naturaleza, ya que son los términos de esta relación los que contribuyen a fijar los límites de las categorías. Esta frontera no es inmanente; por el contrario, lo que es natural en un momento puede ser cultural en otro y viceversa, aunque lo que parece inmutable es la dicotomía como principio estructural (Cavalcanti Schiel, 2007). El aporte de la etnografía a partir del giro ontológico (Descolá, 2005; Viveiros de Castro, 2010) y el cuestionamiento a la universalidad que se arroga la epistemología occidental (de Souza Santos, 2009, 2010) han permitido empezar a atender aquellas otras formas de percibir y habitar el mundo que se alejan de los esquemas instalados por el proyecto colonial en América (Escobar, 2000).

Así, gran parte de los trabajos producidos para el área andina sostienen que el conocimiento sobre el mundo es construido en una relación recíproca entre lo humano, la naturaleza y lo sagrado (van Kessel y Salas, 2002; Rozas Álvarez, 2007; Di Salvia, 2011, 2016; Palacios Liberato, 2014; Jiménez Navia, 2015; Bugallo y Vilca, 2016; García y Roca, 2017). Este vínculo entre lo que otrora se asumió como naturaleza y cultura se presenta como un espacio no contradictorio, muchas veces sostenido por relaciones simétricas entre las entidades a partir de la adquisición de nuevos posicionamientos, posibilitados por una visión no-antropocéntrica del cosmos. Esto llevó a que las interacciones entre humanos y otras especies animales fueran concebidas como relaciones entre sujetos, condición que se reproduce, con sus particularidades, tanto en la América andina como en la amazónica, amén de los particularismos de cada una (Viveiros de Castro, 2013; Peñuelas Peñarroya, 2017). En algunos casos, la dilución de las fronteras ha sido tal que la mejor manera de describir los vínculos entre uno y otras ha sido en los términos de una "humanización del 
ganado" y "una animalización de los hombres" (Rivera Andía, 2016, p. 115), desafiando cualquier clasificación dicotómica.

En la actualidad, sus manifestaciones concretas abarcan un sinnúmero de elementos simbólicos y materiales, en cuya inteligibilidad y trascendencia lo ritual ocupa un lugar privilegiado (Estermann, 1998). Para algunas comunidades, la naturaleza, la tierra y los astros no están separados de la vida humana sino, contrariamente, coadyuvan en la reproducción de la vida social (Gose, 2004; Reyes, 2008; Gil García, 2012; Galdames Rosas y Díaz Araya, 2015; García y Roca, 2017). Referencias actuales de campesinos de Perú y Bolivia mencionan la importancia de estructuras simbólicas asociadas a rituales en torno al agua y la fertilidad. Tal es el caso de los cerros donde viven los ancestros y las piedras huanca que los representan y aseguran la fertilidad de la tierra, los animales y la continuidad del agua, así como otros elementos del espacio con simbología ritual regulados por el ciclo agrícola (Farfán Lobatón, 2002; Robin Azevedo, 2010). Tal vez uno de los elementos más visibles en la manifestación de esta ontología tiene que ver con el significado que adquiere la Madre Tierra en tanto productora de subjetividades. Los relatos recopilados por Arnold, Jiménez y Yapita (2014) refieren que, en todas las fases del trabajo agrícola, la Madre Tierra está presente con cualidades humanas. A ella se la interpela no solo en las épocas de siembra y cosecha, sino ante cualquier acontecimiento importante que requiera una presencia protectora, como puede ser un viaje o la construcción de una nueva casa, o una ocasión ritual o festiva. Este vínculo es reproducido cotidianamente mediante la práctica del dar-recibir en la que se enmarcan los ofrecimientos de comida y demás productos. En el mes de agosto, se retiran las ofrendas del año anterior que la Pachamama no ha comido, para dejarle otras, que la proveerán durante el nuevo año (Páez, Plastiné Pujadas y Marinangeli, 2018)

Estos exiguos ejemplos permiten repensar la existencia de otros entramados posibles en lo que define la relación entre lo humano y lo no humano, donde aquellos elementos que tradicionalmente se utilizaron para definir el ámbito de la cultura -como el lenguaje y la capacidad para simbolizar- ya no son atributos exclusivos del ser humano. Partiendo de esta base interpretativa, procuraremos explorar la forma en que el mundo natural aparece retratado en los relatos de la copla en tanto relato folklórico local, como un elemento para reflexionar, a posteriori, sobre la relación que subyace entre el mundo natural y el mundo humano. A los fines de nuestro objetivo, analizaremos un conjunto de coplas procedentes de la zona norte del Valle Calchaquí, específicamente del departamento de Cachi (Salta), las cuales fueron obtenidas a partir de trabajos de campo y de recopilaciones bibliográficas. Partimos de asociar, siguiendo a Avenburg (2009), a las coplas con prácticas sociales vinculadas a experiencias actuales y pasadas de los grupos que posibilitan acercamientos a las maneras de representar el mundo de aquellos que los producen.

La copla representa una forma poética y musical que combina aportes indígenas e hispánicos en la cultura popular (Racedo, 1996). Algunos investigadores sostienen que, desde el punto de vista musical, se asocia el sistema tonal indígena con la estructura rítmica de la poesía española, lo que remarca su origen mixto (Vega, 1965; Cámara de Landa, 2006). Otros trabajos remarcan un origen español en los siglos XV al XVII y la transformación del género en América conforme con la idiosincrasia del Nuevo Mundo (Kofman, 2013), en tanto hay quienes ponen el acento en el componente americano. $\mathrm{Al}$ respecto, Montellanos (2002, citado en Avenburg, 2016) valida un origen prehispánico en tanto conformaban "melodías ancestrales" preexistentes en el territorio 
americano y vinculadas al canto a la Madre Tierra, que luego fueron incorporadas a una estructura formal a partir de la copla. Asimismo, hay autores que destacan la importancia de considerarlas como composiciones complejas con una entidad propia, construida a partir de identidades sociales y lingüísticas plurales, que perviven en el acervo patrimonial de los pueblos. Es en esta apropiación identitaria y persistencia en que cobra importancia, más que en el debate sobre su dependencia de la literatura americana o española (Taboada de Pérez, 1995).

Se destaca por su carácter anónimo y dinámico, puesto que no se trata de la simple repetición de antiguos textos, sino que continuamente se crean nuevos discursos -incluso a veces esto ocurre durante el momento mismo en que se está cantando-, o se recrean viejas composiciones, y así se les imprimen características propias en función del contexto situacional. Constituye así un elemento cuya función está estrechamente vinculada a la construcción identitaria de los ejecutores, tanto en su dimensión individual como en su proyección social colectiva (Mirande, 2005; Avenburg 2009; Mennelli 2009, 2010). El vínculo con el pasado indígena y con el territorio es un aspecto central retratado en la narrativa de las coplas del noroeste argentino, en una sintaxis anclada en las reivindicaciones por los derechos históricos a la tierra que habitan (Andrade, 2016). En muchos casos, la prevalencia de un relato reclamatorio entra en tensión con escenarios mecantilizados, generados por el turismo, que incorporan a la copla como parte de un paisaje colorido y exotizado (Citro, Mennelli y Torres Agüero, 2017).

\section{La labor etnográfica y el relato de la copla en el Valle Calchaquí}

Las investigaciones que motivaron este trabajo se desarrollaron en las localidades de Cachi y Payogasta, ambas pertenecientes al departamento de Cachi, en el centro oeste de la provincia de Salta (Noroeste argentino). La población del departamento está concentrada en torno a las localidades principales, aunque más del $60 \%$ vive en parajes rurales. Las actividades económicas preponderantes comprenden las labores agrícolas, principalmente para autoconsumo, aunque también se cultivan productos de renta, y en menor medida, la ganadería de ovinos y caprinos (Manzanal, 1987; Cieza, 2010; Pais, 2011; Marinangeli y Páez, 2019). A partir de las últimas décadas, el auge del turismo y los emprendimientos vitivinícolas modificaron significativamente la estructura económica y social de esta región (Plastiné Pujadas y Páez, 2018).

El trabajo de campo incluyó técnicas de recolección de información afines a las investigaciones de tipo cualitativas, como la práctica de la observación participante y la realización de entrevistas, tanto de carácter abierto como semiestructurado, en las que se registraron las coplas. Asimismo, a este corpus de información se sumaron transcripciones de coplas procedentes de Cachi, ya sean recopiladas en libros o como parte de producciones académicas. En todos los casos, se puso especial atención a que los versos procedieran del área de estudio para evitar generalizaciones que pudieran entrar en tensión con las particularidades de la oralidad local.

Los entrevistados -a quienes se llegó a partir de la indicación de otros informantes- fueron seleccionados por su conocimiento del folklore del lugar o por la práctica de la copla; en este último caso, además de las entrevistas nos ofrecieron la narración de algunos versos. Se trata de personas de entre 40 y 
80 años, de ambos géneros y diferentes extractos sociales. Las observaciones en eventos públicos corresponden a contextos asociados con festividades religiosas, exposición de comidas locales junto a espacios abiertos al turismo y otros eventos tradicionales. Finalmente, se pudo acceder a dos obras literarias: una tesis de licenciatura en la que se transcriben algunos versos de diferente autoría y una publicación de una coplera local, que compila versos propios y de otros autores.

En un primer momento se trabajó aislando aquellos versos en los que, de manera directa e indirecta, se aludía a elementos de la naturaleza, animados e inanimados. En una segunda etapa se analizó la forma de aprehensión de estos elementos y el tipo de vínculo -en el caso de que lo hubiera- que se establecía entre ellos y el hombre. Seguidamente, clasificamos el tipo de lógica de relación y trabajamos en conjunto aquellos versos en los que identificamos una lógica común. Cabe mencionar que en una parte importante de estos, el mundo natural aparece representado en calidad de objeto, mediado por una relación de tipo instrumentalista con el mundo social. Este tipo de representación-que puede clasificarse como parte de la lógica dicotómica que atraviesa a la sociedad moderna (Melamed, 2013) - no fue analizada en este trabajo justamente porque puede explicarse sin esfuerzo desde cualquier análisis cultural moderno. En cambio, nos enfocamos en aquellas otras lógicas que pueden considerarse, en algún punto, disruptivas y extemporáneas.

\section{Concepciones acerca de la naturaleza en los relatos de la copla}

A partir del análisis de la forma en la que se reflejan en la copla los elementos del mundo natural y su relación con los sujetos humanos hemos podido identificar algunos mecanismos que reflejan una concepción no independizada del sujeto. Uno de los primeros aspectos analizados se relaciona con la prevalencia de sentimientos y habilidades compartidas por la persona que coplea y elementos de la naturaleza. El desarraigo o la soledad -que operan en el plano emocional-, así como la capacidad de cantar, volar o desplazarse -relacionados con el plano físico- son recreados en los versos como rasgos comunes. Es decir, la apelación al mundo natural se emplea para reafirmar una condición del sujeto y hacerla comprensible, por lo que estos rasgos no parecen excluyentes del mundo social; en todo caso, remiten a un vehículo que pone en diálogo ambos universos.

Diferentes versos dan cuenta de ello: "Yo sufrí mi desarraigo, igualito que una planta"; "Solita estoy en el mundo, solita como el cardón"; “Quién pudiera ser un cóndor, en lo más alto volar"; "No soy cantora de escuela, soy como el ave que canta, mi tonada es un capullo; se hace flor en mi garganta" (Sulca, 2016, p. 23, 79, 97, 77 respectivamente); "Soy como el agua clara, que corre bajo yuyo, que vengo a cantar al año, como el coyuyo" (entrevistado E.A., Cachi, 2018). Algunos de estos, incluso, contribuyen a revalorizar las cualidades del universo natural por sobre el humano. Por ejemplo, en la composición que hace alusión al canto, la coplera identifica sus versos en relación con el canto de las aves, en contraposición a aquel que puede aprenderse en el ámbito cultural ("no soy cantora de escuela"), con lo cual se puede interpretar que se identifica con el primero más que con el segundo.

Además, la coplera se iguala, no con cualquier ave, sino con el ave que canta; es decir, el canto -como la soledad o el desarraigo- parece ser un rasgo que 
tienen en común, y es a partir de este que se genera una identificación, entendida como una construcción constante que se afinca en la contingencia, un proceso de articulación o una sutura (Hall, 2003). En este sentido, la diferencia se presenta como un componente básico en la construcción de las identidades porque opera en la demarcación de los límites simbólicos. En otras palabras, el interior necesita del exterior para definirse (Laclau, 1996). Asimismo, en la referencia a la contraposición entre el canto de las aves y el canto de la escuela podría interpretarse un registro, por parte de la coplera, del antagonismo entre naturaleza y cultura: el primero, vinculado a una identidad elegida; el segundo, a una institución que, al menos en estos versos, aparece como resistida.

En otras composiciones analizadas, no obstante, la identificación no opera a partir de la comparación entre dos entidades delimitables y diferenciadas (humano-animal, humano-planta, humano-objeto), sino que el primero se reconoce en el segundo. "Soy la vaca que viene balando, por medio de las peñas, vengo pasando cañadas, vengo buscando la senda" (entrevistado E.A., Cachi, 2015). Al igual que en los casos anteriores, la identificación se sostiene sobre la base de una subjetividad compartida, que no apela a rasgos físicos sino a actitudes/comportamientos. En otras palabras, se vigoriza en el terreno de la agencia.

Por otro lado, la humanización del mundo natural es una característica recurrente en las coplas que pudimos analizar. Uno de los ejemplos de mayor claridad es la referencia al llanto de animales u objetos, en relación de simetría con la emotividad humana. Algunos versos reflejan esta cualidad: "Ya se viene el carnaval, por medio de los cardones, haciendo llorar las piedras, cautivando corazones" (Sulca, 2016, p. 102), "Ayer tarde salí al campo, en un llanto desmedido, hasta las aves lloraron, de ver un amor perdido" (Liquin, 2013). En la primera de las coplas, la referencia al llanto procura expresar el poder de sensibilización del carnaval, que alcanza tanto a las piedras como a las personas. En la segunda, refleja la empatía de las aves con la tristeza de la coplera. La emoción, ya sea volcada en la forma de alegría o de tristeza, es vivenciada también por el mundo natural, los objetos y los animales, y representa un punto de comunión con los humanos. Aquí, esta cualidad emocional compartida no tiene características diferentes según se trate de las aves o de la coplera. Por el contrario, exterioriza la capacidad de ambos de sensibilizarse ante una situación de tristeza/angustia que los afecta por igual. En otros términos, la naturaleza no solo aparece dotada de cualidades humanas, sino que también se asocia a una noción de simetría.

De acuerdo con Descola (2012), la interioridad hace referencia a aquella gama de propiedades que solemos reconocer como "espíritu", "alma" o "conciencia" y que se describe a partir de la intencionalidad, subjetividad, reflexividad, afectos, aptitud para significar o soñar, que puede también incluir principios inmateriales causantes de la animación como el aliento o la energía vital (Descola, 2012, p. 182). Esto que el autor describe para la Amazonía también es mencionado en estudios etnográficos realizados en comunidades altoandinas a partir de diferentes denominaciones: sami, anima, animu, kamaquen, kallpa (La Riva González 2005; Rozas Álvarez, 2007; Allen 2015, 2016; García y Roca 2017). Se corresponden con la idea de que todas las entidades que existen en el universo están impregnadas de espíritu, sustancia o fuerza, y que en muchos casos son más potentes cuando pertenecen al mundo físico que al humano. Uno de los ejemplos más contundentes es representado en la alusión a la Madre Tierra, cuyas coplas retomaremos más abajo. Según Espinosa Soriano (1990, p. 435), "No era precisamente el alma tal como se la entiende en las religiones 
del viejo continente; sino más bien un principio de movimiento de las cosas, tanto seres humanos como objetos del mundo".

En las coplas también hay objetos que aparecen provistos de valoraciones especiales, como es el caso de las tinajas, cuya elaboración se relaciona con el nacimiento, y las funciones que va a desempeñar después, con comportamientos humanos: "La tinaja cuando nace, no sabe si es su destino, ayudar para la sed o al viejo oficiar el vino. Ay tinajita de barro, Dios quiera la suerte, guardar tu cuerpo mi cuerpo, cuando me llegue la muerte" (copla de Martín Alemán Monico, en Sulca, 2016, p. 86). Aquí, la función de contener líquidos es referida como la actitud de ayudar para calmar la sed, y la utilización de la tinaja como urna funeraria -característica del entierro en esta región en tiempos prehispánicos- es significada como el acto de contener el cuerpo humano dentro del propio cuerpo de arcilla. Cabe mencionar que la utilización de las vasijas para funciones relacionadas con el entierro humano es una práctica que dejó de utilizarse con la presencia cristiana en América y pervive solamente en el registro arqueológico (Ambrosetti, 1907; Debenedetti, 1908; Baffi, Baldini y Pappalardo, 2001).

En otros relatos se ha podido visualizar la referencia a vínculos filiales con elementos de la naturaleza, a partir de los cuales se puede interpretar un sentido de pertenencia. "Yo nací en el campo, soy hijo de la perdiz, de toditos los hermanos, soy el más infeliz" (Sulca, 2016). Este tipo de relación no ha sido la más frecuente en los versos analizados. No obstante, la presencia por sí misma es por demás sugestiva porque, si bien es la forma que la autora encuentra para relatar su origen en el campo, el entorno silvestre pierde el lugar de tal para asumir la forma de un vínculo parental. Similares experiencias han sido identificadas en los relatos de Rivera Andía (2016) para la sierra peruana, en alusión a la forma en que los dueños del ganado denominan a sus animales. Referencias afines hemos encontrado en las coplas recopiladas por Aretz (2000) para La Rioja, donde, si bien de manera menos directa, es posible identificar una filiación entre el autor y el referente natural. "Yo soy rama de los troncos, de los troncos que se acabaron" (vidalita de Andrés Flores, Aretz, 2000, p. 28). Aquí hay, además de una relación de pertenencia, una composición que combina dos tiempos verbales: presente (soy) y pasado (acabaron), unidos a partir de una relación parental pero también temporal.

Retomando al Valle Calchaquí, con frecuencia, la naturaleza también es incorporada en los relatos que analizamos a partir de la interpelación. Esto es más evidente tal vez en aquellos versos que se relacionan con la Pachamama, la que es evocada como madre y dadora de la vida en la tierra. "Pachamama, santa tierra, no me comas todavía, voy a cantar esta noche, y mañana todo el día", "De tu vientre Pachamama, como agua cristalina, brotan danzas y bagualas, viva mi tierra argentina", "Cuidamelos Pachamama, con tu munay de mujer", "Desde lejos i'venido, como he podido i'llegau, para dejarte en tu vientre, todo mi humilde cantar" (Sulca, 2016, p. 106, 106, 108, 108 respectivamente). En las coplas subyacen algunas valoraciones a partir de las cuales tiene lugar la reclamación, que posicionan a la entidad como una figura de poder, maternal, protectora y femenina. De ella depende la reproducción de la vida, pero no solo de plantas y animales sino también la humana, como se puede notar en el primero de los versos, cuando le pide que no se la coma, que quiere cantar esa noche y el día siguiente. Ese concepto de reproducción parece aplicarse al mundo de lo físico y también de lo social, como lo expresa el verso siguiente en el que ubica el mundo de las tradiciones (danzas y bagualas) en el vientre de la Pachamama. La reiterada referencia a su vientre es uno de los elementos 
más emblemáticos en torno a su condición de creadora, y si bien esta creencia hunde sus raíces en el mundo prehispánico, el carácter de madre subyace en todas representaciones que se tiene de ella en la actualidad (Páez et al., 2018). Esto mismo es rescatado en el relato de copleras de Amaicha, al sur de nuestra área de estudio, que comparte con el Valle Calchaquí profundas raíces históricas y cercanos vínculos culturales. En los versos analizados por Andrade (2016) se hace mención a la Pachamama como una mujer con ropas gastadas y faldas grandes, que vive en los cerros cuidando a los animales y lleva consigo una caja y un instrumento para tejer. Aparece, así, una relación de la entidad con el carácter protector y el género femenino al que veníamos haciendo referencia, al que además se suma el propio colectivo que representan.

\section{Una explicación para la simetría}

Tras la identificación de estas otras concepciones que subyacen en el contenido literario de los versos populares contemporáneos del valle y que, como mencionamos anteriormente, conviven con formas más instrumentales de objetivar la naturaleza, surge la pregunta acerca del origen o, al menos, de un punto de referencia con el cual anclarlas.

Algunos estudiosos del folklore local se han preocupado por vincular las producciones musicales con otras manifestaciones precedentes, dentro y fuera del continente. Al respecto, Juan Alfonso Carrizo (1978) -que logró compilar una gran cantidad de coplas del noroeste argentino- rescata elementos que las relacionan con la producción del Siglo de Oro de la literatura española, en particular a partir de la alusión a personajes o prácticas de origen cristiano. Si bien en su análisis acerca de los vínculos con la poesía de los siglos XVI y XVII no hay referencias a la naturaleza, la revisión de estas composiciones nos permitió trazar algunos puntos de confluencia con las coplas que analizamos. De gran riqueza artística y en sintonía con el auge político de España, la literatura hispana de los siglos XVI y XVII presenta matices según se trate de la etapa renacentista o barroca (Canavaggio, 1994).

En diferentes autores clásicos de la literatura española es posible rastrear una referencia a elementos de la naturaleza, que de manera más simple ya estaba presente en lo medieval. Así, "El Renacimiento incorpora la visión de la Naturaleza; el Barroco, en una actitud de aproximación hacia la realidad toda hará aparecer, además, no solo los temas del árbol, las flores y los pájaros, sino también el bodegón" (Orozco Díaz, 1945, p. 99). La descripción y exaltación de los elementos naturales destaca en las obras clásicas ${ }^{1}$ de autores como Francisco de Quevedo, Francisco de Rioja, sor Juana Inés de la Cruz, Esteban Manuel de Villegas, Rivas, Garcilaso de la Vega y Luis de Gongora y Acoite, entre otros. De acuerdo con Martínez Valls (2008), la belleza de la naturaleza refleja las aspiraciones y las emociones de los autores, ese es el sentido por el cual se la humaniza e interpela:

Con mi llorar las piedras enternecen su natural dureza y la quebrantan; los árboles parece que se inclinan; ${ }^{2}$ las aves, que me escuchan cuando cantan, con diferente voz se condolecen y mi morir, cantando, me adivinan; las fieras que reclinan su cuerpo fatigado, dejan el sosegado sueño para escuchar mi llanto triste. (Garcilaso de la Vega, 1984, p. 126)

Entonces, ¿es posible concebir alguna imagen de simetría entre el poeta y el paisaje en la literatura hispana, en sintonía con lo que se pudo observar en la
1. Revisión de los poemas compilados en García (2009).

2. Estos primeros versos fueron retomados en Martínez Valls (2008) para ejemplificar su propuesta. 
copla? ¿Cuál es el sentido de tal exaltación de los elementos del mundo natural? La imagen del goce e inspiración que se transmite en los versos posiciona al poeta en el centro de las composiciones. Así, la naturaleza no es sin el poeta, sino para el poeta, en un pasaje que le permite expresar un mundo idealizado que ubica a sus emociones, sentimientos o deseos en el centro de lo creado. De acuerdo con Martínez Valls (2008), "la naturaleza está estrechamente ligada al hombre, lo define y funda su ser en el mundo. Su evocación sirve a la discreta pero segura revelación de las ideas del poeta". En consonancia con el antropocentrismo que caracteriza las ideas del Renacimiento, aun el otorgamiento de actitudes humanas al mundo natural es un recurso que le permite al poeta expresarse en primera persona. Podría decirse entonces que, a diferencia de lo observado en los versos de la copla, la humanización del mundo natural podría ser entendida en auxilio de la centralidad del hombre, sus emociones y sentimientos.

Si retomamos los mecanismos descriptos para las coplas, en el caso de los versos hispanos no hemos podido rastrear ejemplos de identificación ni tampoco de filiación, además de las diferencias en la representación de los paisajes, europeos en un caso, americanos en el otro. Así, como contrapunto de lo propuesto por Carrizo en cuanto a los vínculos de las coplas con la literatura española de los siglos XVI y XVII, hay elementos que subyacen en lo profundo de sus representaciones que probablemente puedan explicarse mejor apelando a la idiosincrasia americana, tal como fuera propuesto por Aretz (2000). Al respecto, la autora relaciona, desde el punto de vista musical, los registros de bagualas y vidalitas de La Rioja con el componente prehispánico local, y establece que "es urgente que ampliemos el horizonte de los estudios etnomusicológicos a nuestra América, y sobre todo a la América precolombina" (Aretz, 2000, p. 44).

Siguiendo esta propuesta, aunque desde un enfoque centrado, no en las formas musicales, sino en los aspectos ontológicos, resultó interesante remontarnos al registro indígena en el interés de encontrar un anclaje para estas concepciones otras acerca del mundo natural. La revisión de aquellas formas de ser y habitar el mundo de sociedades alejadas del proyecto de modernidad que se instala en América en el siglo XVI (Quijano, 2000) no es novedosa en el pensamiento contemporáneo latinoamericano. Al respecto, Escobar (2000) propone retomar algunos ejes invisibilizados en las epistemologías suramericanas que involucran formas de relación que preexisten en nuestro territorio y que tienen gran poder explicativo acerca de las idiosincrasias locales. La concepción circular del tiempo; la reproducción de la vida a partir de la "crianza"; la no separación entre humanos y naturaleza, individuo y comunidad, comunidad y dioses; la relación entre circuitos de orden biofísico, humano y supernatural, son algunos de los ejemplos que él menciona y que pueden representar un punto de partida para entender la simetría que se observa en las coplas y que no es posible explicar apelando a las lógicas de pensamiento occidental contemporánea ni a las de los siglos XVI y XVII.

El registro arqueológico local es profuso y diverso, de acuerdo con una ocupación de muchos siglos previos a la llegada europea, por lo que un análisis de todas las manifestaciones cultuales requeriría más espacio del que disponemos en este artículo. Por eso, orientados por el interrogante puntual acerca de la simetría, es interesante retomar un tipo de materialidad que se presenta como problemática ante una visión dicotomizada del mundo. Para los últimos cinco o seis siglos previos a la presencia española, en el territorio del Valle Calchaquí norte se han identificado unos bloques de piedra -denominados huancas-, ubicados en medio de los campos utilizados para cultivo por las poblaciones 
que allí habitaban. Su forma -alargada o amesetada- y su tamaño, que no supera 1,5 m, hubieran hecho posible su remoción para optimizar el espacio de siembra y facilitar el trabajo sobre las parcelas, pero eso no ocurrió y aun en la actualidad se conservan algunos ejemplos en medio de terrenos utilizados para el cultivo (Páez y Mariangeli 2016; Páez et al. 2016). Esto ha motivado, incluso, una modificación en el trazado de los surcos de siembra, que en lugar de ser lineales se orientan de forma circular, rodeando las piedras paradas, lo cual condiciona las tareas de labranza. Consultados sobre su significado, los pobladores refieren una función ritual vinculada con la fertilidad, y mencionan que hasta hace algunas generaciones todavía se realizaban ofrendas a la Madre Tierra, y que si bien ya no se realizan, no se remueven de sus lugares por el significado que en otro tiempo tuvieron para sus abuelos (Páez, Marinangeli y Prieto, 2016; Páez et al., 2019).

La referencia a piedras con funciones rituales aparece muy temprano en las crónicas del siglo XVII (Hernández Príncipe, 1622; Avendaño, 1648; Arriaga, 1698). Las interpretaciones generadas a partir de estos registros indican que en ellas se conjugan los ancestros y la fertilidad como condición de reproducción del grupo, pero también una dimensión material que no existe de manera escindida. Consideradas como una materialización de los ancestros, podrían haber estado relacionadas con la protección de los centros urbanos, o con la fertilidad de las parcelas sembradas dependiendo del lugar en donde estaban ubicadas (Duviols, 1978, 1979). Actualmente, representan un registro profuso dentro del del área andina (García Azcárate, 1996; Aschero, 2007; Manzo, 2010; Tantaleán y Leyva, 2011; Burger y Salazar, 2015) y representan el vínculo de los humanos con otras entidades, aún más poderosas, con las que es posible relacionarse en los términos que ofrece la reciprocidad como el metalenguaje comprendido por todas las entidades del cosmos (Cavalcanti Schiel, 2015). Las piedras no califican como materia inerte sino, por el contrario, son entidades poderosas, que interpelan a los sujetos humanos y tienen la capacidad de promover la fertilidad y proteger la vida en la tierra. De este modo, la relación con la naturaleza (la tierra, el cosmos, la lluvia) no se establece en los términos de un esquema sujeto-objeto, en que los segundos son pasibles de ser controlados y manipulados. Por el contrario, los agentes del cosmos, así como los antepasados, adquieren subjetividades propias y se constituyen en sujetos sociales con una agencia activa en la reproducción de la vida (Giovannetti y Páez, 2019).

Esto traza una diferencia significativa en relación con nuestros esquemas de realidad y representación, entre los cuales media una relación convencional que apela a la capacidad de simbolizar. Es decir, las piedras no simbolizaban a los ancestros para los pueblos prehispánicos, sino que efectivamente lo eran. Algo de aquello se puede rastrear cuando se analiza la creencia en la Pachamama que tienen los pobladores del Valle Calchaquí. El hueco en la tierra que se hace para dejar la ofrenda no interpela a una materialidad que representa a la entidad, sino que es la entidad misma y por eso se le dejan las mejores comidas y bebidas o se le ofrecen tabaco y coca. En otras palabras, se le ofrece lo mismo que los sujetos humanos necesitan y disfrutan.

Finalmente, aquí también es posible repensar otras nociones de temporalidad, como propone Escobar (2000). La noción contemporánea de ancestro/ancestralidad, tal como la entendemos hoy, consigna un tiempo pretérito dentro de los esquemas temporales modernos, que se relacionan con el presente solo a partir de un ejercicio de memoria. Es decir, se comprende en el marco de un esquema lineal y progresivo. Por el contrario, si los ancestros tenían agencia en la forma de las piedras huanca y si interactuaban con los sujetos humanos 
y demás entidades del mundo físico presentes en un mismo plano temporal, no solo hay que pensar que la noción lineal no aplica sino, además, tampoco los mecanismos que funcionan en la sutura entre pasado y presente. De esta forma, el tiempo, al igual que el espacio, no representa una dimensión alienada de la experiencia ni preexistente a los sujetos humanos y no humanos y, por ende, se define con y a través de ellos.

\section{Discusión y conclusiones}

El vínculo cultural e histórico entre quienes reproducen actualmente las coplas y la población indígena que habitó estos territorios no ha pasado desapercibido para los estudiosos contemporáneos (Racedo, 1996; Aretz, 2000), aunque a veces solo se alerte sobre versos que refieren a estilos de vida diferentes a los actuales (Polo y Pozzo, 2011). Particularmente para el caso que nos convoca, la persistencia de prácticas indígenas en la cotidianeidad de los pobladores de Cachi trasciende el relato coplero y atraviesa diferentes ámbitos de la vida de los habitantes. La comida, la medicina, las formas de cultivo, las relaciones interpersonales o la forma de aprehender el paisaje son solo algunos de los muchos aspectos que han sido constantemente significados desde la América prehispánica hasta nuestros días.

Lo singular del registro de las huancas, por el cual traemos esta y no otra materialidad a la discusión, se relaciona con la forma clara en que los elementos del cosmos se constituyen como sujetos; es decir, agentes sociales con un protagonismo equiparable al humano en lo vinculado a la reproducción social. Esta lógica simétrica que permea los diferentes espacios y momentos de la vida prehispánica de los grupos locales encuentra algunos puntos de anclaje con los relatos etnográficos que hemos repuesto en diferentes pasajes a lo largo del trabajo. Esto no implica que se puedan homologar dinámicas sociales extemporalmente, sino que estas confluencias que advertimos en el registro social -pasado y presente- requieren ser explicadas.

Podemos pensar que la transversalidad que existe entre el repertorio material (pasado) y oral (presente) está sostenida en las particularidades del proceso histórico posterior a la conquista. Una gran parte de los esquemas de significación americanos han sido deliberadamente desarticulados en el siglo XVI y en los siglos siguientes, amén de las estrategias llevadas adelante por las políticas de colonización, primero, y globalización, después. Y es posible imaginar que nuevos actores sociales y políticos -internos y externos- coadyuvaron para que la modernidad se apropiara cada vez más de las tradiciones locales.

Los primeros resultados en torno al relato coplero nos permitieron pesquisar otras conceptualizaciones en torno a lo natural que escapan a la episteme moderna y que tampoco se pueden sostener como trazos relictuales de la poesía hispana contemporánea a la conquista y colonización. ¿Sería posible que estos grafismos que parecen no encajar en los engranajes aceitados de la ingeniería actual representen persistencias de un pasado atravesado por una construcción diferente de los seres y sus relaciones? Esto de ninguna manera significa que el pasado pueda conservarse a la manera de vitrina de museo. En cambio, si pensamos en la copla como un espacio creativo y permeado por el contexto situacional pero también por el contexto histórico, entonces la memoria social, que "retiene del pasado solo lo que aún está vivo o es capaz de vivir en la conciencia del grupo que la mantiene" (Halbwachs, 2006, p. 102), 
constituye el obligado recoveco para explicar estas otras lógicas subyacentes, que tal vez podríamos llamar otras ontologías en resistencia.

Finalmente, es importante recordar que ningún proceso mnemónico se explica espontáneamente. Por eso, el análisis de las conceptualizaciones acerca de la naturaleza que aparecen en las coplas requiere repensar el escenario indigenista americano en diálogo con los proyectos políticos y los esquemas ideológicos que construyeron y reconstruyeron la identidad de los pueblos (Lyall, 2010). Resta descubrir si la semántica casi subterránea de estas formas de representar el mundo constituye una estrategia suficiente para preservar estas memorias del avance monolítico de la historia.

\section{Financiamiento}

El financiamiento para las tareas de campo y laboratorio provino del Consejo Nacional de Investigaciones Científicas y Técnicas (PIP 11220150100783), la Agencia Nacional de Promoción Científica y Tecnológica (PICT 2014-1907) y la Universidad Nacional de La Plata (PPID/No37).

\section{Agradecimientos}

Deseamos expresar nuestra gratitud a las comunidades de Cachi y Payogasta, por su afecto y hospitalidad, a las autoridades del Museo Pío Pablo Díaz, de la localidad de Cachi, y al Museo Antropológico de Salta por el apoyo, y a los revisores anónimos, que ayudaron a mejorar la versión original del manuscrito. La responsabilidad de lo expresado, no obstante, es exclusiva de los autores.

\section{Biografía}

María Cecilia Páez. Licenciada en Arqueología de la Escuela de Arqueología, Universidad Nacional de Catamarca. Doctora en Ciencias Naturales en la Facultad de Ciencias Naturales y Museo, Universidad Nacional de La Plata. Investigadora Independiente del CONICET. Desarrolla sus actividades en el Museo de La Plata (La Plata, Buenos Aires, Argentina).

Alejandro Martínez. Licenciado en Antropología de la Facultad de Ciencias Naturales y Museo, Universidad Nacional de La Plata. Doctor en Ciencias Naturales en la Facultad de Ciencias Naturales y Museo, Universidad Nacional de La Plata. Es docente-investigador en la Facultad de Ciencias Naturales y Museo (La Plata, Buenos Aires, Argentina).

Francisco Riegler. Alumno avanzado de la Licenciatura en Antropología de la Facultad de Ciencias Naturales y Museo, Universidad Nacional de La Plata (La Plata, Buenos Aires, Argentina). Pasante el proyecto Ancestralidad, Memoria y Territorio en el sector norte del Valle Calchaquí (Salta, Argentina), entre los siglos X y XV (FCNyM, UNLP).

Catalina Martínez. Egresada de la Licenciatura en Antropología de la Facultad de Ciencias Naturales y Museo, Universidad Nacional de La Plata (La Plata, Buenos Aires, Argentina). Pasante el proyecto Ancestralidad, Memoria y Territorio en el sector norte del Valle Calchaquí (Salta, Argentina), entre los siglos X y XV (FCNyM, UNLP). 


\section{Q Referencias bibliogtráficas}

"Allen, C. (2015). The Whole World Is Watching: New Perspectives on Andean Animism. En T. Bray (Ed.). The Archaeology of Wak'as (pp. 23-46). Boulder, Colorado: University Press of Colorado.

»Allen, C. (2016). The Living Ones: Miniatures and Animation in the Andes. Journal of Anthropological Research 72(4), 416-441.

"Ambrosetti, J. B. (1907). Exploraciones arqueológicas en la Ciudad Prehistórica de 'La Paya' (Valle Calchaquí, Prov. de Salta). Buenos Aires: Facultad de Filosofía y Letras, Publicaciones de la Sección Antropológica 3.

"Andrade, I. (2016). Os cantos das copleras em Amaicha del Valle: performatividade voco-sonora, corpos em devir e sentido de lugar no Noroeste Argentino (tesis de grado). Programa de Posgraducación en Música de la Universidad Federal de Rio Grande do Sul, Brasil.

» Aretz, I. (2000). Cantos de La Rioja remanentes de culturas prehispánicas. Una nueva tesis a discutir, Revista del Instituto de Investigación Musicológica "Carlos Vega", 16, 17-45. Recuperado de http://bibliotecadigital.uca.edu.ar/repositorio/revistas/cantos-la-riojaremanentes.pdf

» Arnold, D., Jiménez, D. y Yapita, J. (2014). Hacia un orden andino de las cosas. La Paz: Instituto de Lengua y Cultura Aymara.

» Arriaga, P. de (1968 [1621]). Extirpación de la idolatría del Perú. En F. Esteve (Ed.). Crónicas peruanas de interés indígena (pp. 191-277). Madrid: Atlas [Biblioteca de Autores Españoles, t. CCIX].

"Aschero, A. (2007). Íconos, huancas y complejidad en la Puna sur argentina. En A. Nielsen, M. Rivolta, V. Seldes, M. Vázquez y P. Mercolli (Comps.). Procesos sociales prehispánicos en el sur andino: la vivienda, la comunidad y el territorio, tomo II (pp. 259-290). Córdoba: Brujas.

» Avenburg, K. (2009). Coplas y cumbia. Música y performance en el carnaval de Iruya (Salta, Argentina). Trabajo presentado en VIII Reunión de Antropología del Mercosur: Diversidad y Poder de América Latina, Ciudad Autónoma de Buenos Aires, 29 de septiembre al 2 de octubre. Recuperado de http://rdd.undav.edu.ar/pdfs/ev8/ev8.pdf

" Avenburg, K. (2016). Indígenas y “aggiornados”. Coplas y cumbia en el carnaval de Iruya (Salta, Argentina). Trans. Revista transcultural de música, 20, 1-21. Recuperado de http:// www.sibetrans.com/trans/public/docs/oza-trans-2016.pdf

» Avendaño, F. de (1648). Sermones de los misterios de nuestra santa fe católica en lengua castellana, y la general del Inca. Lima: Jorge López de Herrera.

» Baffi. E., Baldini, L. y Pappalardo, R. (2001). Entierro de un párvulo en urna. Ruiz de los Llanos (Valle Calchaquí, Salta, Argentina). Boletín del Museo de Arqueología y Antropología, 4(3), 63-86.

" Bugallo, L. y Vilca, M. (2016). Wak'as, diablos y muertos. Alteridades significantes en el mundo andino. San Salvador de Jujuy: Universidad Nacional de Jujuy-EDIUNJU-IFEA.

» Burger, R., y Salazar, L. (2015). La cerámica de Coscopunta, un sitio del Período Intermedio Tardío en la provincia de Carhuaz, Callejón de Huaylas, Perú. Bulletin de l'Institut français d'études andines, 44(1), 23-52.

" Cámara de Landa, E. (2006). Entre Humahuaca y La Quiaca. Mestizaje e identidad en la música de un carnaval andino. Valladolid: Universidad de Valladolid. 
Canavaggio, J. (1994). Historia de la literatura española. El siglo XVI. Barcelona: Ariel.

»Carrizo, J. A. (1978). El cristianismo en los cantares populares. Buenos Aires: Dictio.

»Cavalcanti Schiel, R. (2007). Las muchas naturalezas en los Andes. Periferia, 7, 1-11.

»Cavalcanti Schiel, R. (2015). Relativizando la historicidad. Memoria social, cosmología y tiempo en los Andes. QuAderns-e, 20(2), 85-115.

»Cieza, G. (2010). Procesos organizativos y acceso a la tierra en el Valle Calchaquí (tesis de doctorado). Universidad Nacional de La Plata, La Plata, Argentina.

»Citro, S., Mennelli, Y. y Torres Agüero, S. (2017). “Cantando al patrimonio...”: las expresiones indígenas, entre discursos globales y creatividades locales. Antípoda. Revista de Antropología y Arqueología, 29, 175-197.

»Debenedetti, S. (1908). Excursión arqueológica a las ruinas de Kipón. Revista de la Universidad de Buenos Aires (sección Antropología), VIII (4), 1-56.

》Descola, P. (2012). Más allá de naturaleza y cultura. Buenos Aires: Amorrortu.

»De Souza Santos, B. (2009). Una epistemología del Sur. La reinvención del conocimiento y la emancipación social. México: Siglo XXI; Consejo Latinoamericano de Ciencias Sociales (CLACSO).

»De Souza Santos, B. (2010). Descolonizar el saber, reinventar el poder. Uruguay: Trilce.

»Di Salvia, D. (2011). For a dialectic of Andean nature. A philosophical-anthropological approach to the beliefs of the Quechua in Apus and Pachamama. Gazeta de Antropologia, 27(1), art. 13. Recuperado de http://www.gazeta-antropologia.es/wp-content/ uploads/G27_13Daniela-di-Salvia.pdf

»Di Salvia, D. (2016). Contribución a la ontología animista andina: funciones, poderes y figuras en los cultos telúricos de los Andes sur-peruanos. Revista Española de Antropología Americana, 46, 97-116.

»Duviols, P. (1978). Un symbolisme andin du double: La lithomorphose de l'ancêtre. En Actes du XLIle Congrès international des américanistes: Congrès du centenaire (pp. 359-364). París: Societé des américanistes.

»Duviols, P. (1979). Un symbolisme de l'occupation, de l'occupation, de l'aménagement et de l'exploitation de l'espace: Le monolithe "huanca» et safonctiondans les Andes préhispaniques. L'Homme, 19(2), 7-31.

»Escobar, A. (200o). El lugar de la naturaleza y la naturaleza del lugar: ¿globalización o postdesarrollo, En La colonialidad del saber: eurocentrismo y ciencias sociales. Perspectivas latinoamericanas. Buenos Aires: CLACSO.

»Espinoza Soriano, W. (1990). Los Incas. La Victoria: Amaru.

»Estermann, J. (1998). Filosofía andina: Estudio intercultural de la sabiduría autóctona andina. Quito: Abya-Yala.

» Farfán Lobatón, C. (2002). El simbolismo en torno al agua en la comunidad de HuarosCanta. Bulletin Institut Français d'Etudes Andines, 31(1), 115-142.

» Galdames Rosas, L. y Díaz Araya, A. (2015). Piedra en la piedra, ¿el hombre dónde estuvo? Percepción y significado de la piedra en la geografía sagrada de las sociedades andinas. Runa, 36(2), 5-23.

" García, F. y Roca, P. (2017). Pachakuteq. Una aproximación a la cosmovisión andina. Venezuela: Fundación editorial El perro y la rana.

» García Azcárate, J. (1996). Monolitos-huancas: un intento de explicación de las piedras de Tafí (Rep. Argentina). Chungará, 28(1-2), 159-174. 
» Garcilaso de la Vega, I. (1984). Égloga I. En E. Rivers (Ed.). Poesías castellanas completas (pp. 126). Madrid: Castalia.

" Gil García, F. (2012). Lloren las ranas, casen las aguas, conténganse los vientos. Rituales para llamar la lluvia en el centro y sur andino. Revista Española de Antropología Americana, 42(1), 145-168.

» Giovannetti, M. y Páez, M. C. (2019). Poder, reciprocidad y ordenamiento del cosmos en El Shincal de Quimivil (Catamarca, Argentina). Revista Arqueología 26(1), 13-38.

"Gose, P. (2004). Aguas mortíferas y cerros hambrientos: Ritos agrarios y formación de clases en un pueblo andino. Quito: Abya-Yala.

» Halbwachs, M. (2006). A memória coletiva. San Pablo: Centauro.

» Hall, S. (2003). Introducción: ¿quién necesita 'identidad'? En S. Hall y P. Du Gay (Comps.). Cuestiones de identidad cultural (pp. 13-39). Buenos Aires: Amorrortu.

» Hernández Príncipe, R. (1986 [1622]). Idolatrías en Recuay, Provincia de Huailas. En P. Duviols (Ed.). Cultura andina y represión. Procesos y visitas de idolatrías y hechicerías, Cajatambo, siglo XVII (pp. 483-507). Cusco: Centro de Estudios Rurales Andinos "Bartolomé de las Casas".

" Jiménez Navia, M. (2015). Apachita Waraqu: la descolonización expresada en las prácticas ch'ixi durante el mes de la Pachamama. T'inkazos, 37, 173-19o.

» Kofman, A. (2013). La copla española en América Latina. La Colmena, 79, 65-78.

»Laclau, E. (1996). Emancipación y diferencia. Buenos Aires: Ariel.

» La Riva González, P. (2005). Las representaciones del animu en los Andes del sur peruano. Revista Andina, 41(1), 63-88.

"Latour, B. (2007). Nunca fuimos modernos. Ensayo de antropología simétrica. Buenos Aires: Siglo XXI.

"Liquin, M. (2013). "Las cajeadas en Cachi” Provincia de Salta (tesis de licenciatura). Universidad Nacional de Arte, Ciudad Autónoma de Buenos Aires, Argentina.

» Lyall, A. (2010). Los usos de la memoria: poder y resistencia en Cayambe. Quito: Facultad Latinoamericana de Ciencias Sociales (FLACSO); Abya Yala.

" Manzanal, M. (1987). Pobreza y marginalidad en el Agro Argentino: la producción agrícola y su comercialización en Cachi, Salta. Buenos Aires: Centro de Estudios Urbanos y Regionales.

" Manzo, A. (2010). De la extirpación de las idolatrías. Buenos Aires: Dunken.

» Marinangeli, G. y Páez, M. C. (2019). Transformaciones en la organización agrícola de pequeños productores del Valle Calchaquí Norte (departamento de Cachi, Salta). Diálogo Andino, 58(1), 101-113.

" Martínez Valls, M. (2008). Une approche de la poésie espagnole des XVème et XVlème siècles. La Clé des Langues. Recuperado de http://cle.ens-lyon.fr/espagnol/litterature/ litterature-espagnole/poesie/une-approche-de-la-poesie-espagnole-des-xveme-etxvieme-siecles

》 Melamed, A. (2013). Una aproximación al debate contemporáneo sobre la modernidad. En J. C. Morán. Por el camino de la filosofía, la plata: Pensar de nuevo la modernidad, 4ta. ed. (pp. 163-173). La Plata: De la Campana.

» Mennelli, Y. (2009). "Cuerpos que importan" en el contrapunto de coplas del carnaval humahuaqueño. Revista Avá, 16, 189-209. 
" Mennelli, Y. (2010). Carnavales de cuadrilla en Humahuaca: características principales y dilemas actuales. En E. Cruz (Ed.). Carnavales, fiestas y ferias en el mundo andino de la Argentina (pp. 75-109). Salta: Purmamarca Ediciones.

» Mirande, M. E. (2005). Ábrase esta rueda, vuélvase a cerrar. La construcción de la identidad mediante el canto de coplas. Cuadernos, 27(1), 99-110.

» Orozco Díaz, E. (1945). De lo Humano a lo Divino (Del paisaje de Garcilazo al de San Juan de la Cruz). Revista de la Universidad de Oviedo, 6, 99-123.

»Páez, M. C. y Marinangeli, G. (2016). Huancas and Rituals of Fertility in the Farming Landscape of the Northern Calchaquí Valley (Salta, Argentina). Latin American Antiquity, $27(1), 115-131$.

»Páez, M. C., Marinangeli, G. y Prieto, M. E. (2016). Significación e historicidad en el paisaje campesino del Valle Calchaquí Norte (provincia de Salta, Argentina). Historia Agraria, 68, 137-156.

"Páez, M. C., Plastiné Pujadas, I. y Marinangeli, G. (2018). Creencias indígenas en contextos de modernidad. La Pachamama en Cachi (Salta). Revista Estudios Antropología Historia. Nueva Serie, 5, 27-39.

»Páez, M. C., Marinangeli, G., Pifano, P., Plastiné Pujadas, I., Gianelli, J., Riegler, F. y Bonfigli, F. (2019). Ritualidad y memoria en el paisaje social del Valle Calchaquí Norte. Actas de las VI Jornadas de Antropología Social del Centro. Proyecciones Antropológicas en Contextos de Cambio Social (pp. 1226-1237).

»Pais, A. (2011). Las transformaciones en las estrategias de reproducción campesinas en tiempos de globalización. El caso de Cachi en los Valles Calchaquíes (tesis de doctorado). Universidad Nacional de Córdoba, Córdoba, Argentina.

"Palacios Liberato, L. (2014). Una aproximación a la filosofía andina prehispánica en los fragmentos, relatos o testimonios registrados durante la colonización española. Episteme, 6(2), 167-178.

"Peñuelas Peñarroya, A. (2017). Relaciones entre habitantes humanos y no humanos en los Andes ecuatorianos: el caso de la comunidad indígena campesina de Talahua (tesis de maestría). FLACSO, Ecuador.

»Plastiné Pujadas, I. y Páez, M. C. (2018). Mestizaje y resistencia en torno a la creencia en la Pachamama en el Valle Calchaquí Norte (Salta, Argentina). Boletín de Antropología, 57(1), 95-106.

"Polo, M. y Pozzo, M. (2011). Vigencia y sentido de las prácticas musicales tradicionales en la actualidad. El caso de la baguala y la vidalita andina en San Blas de los Sauces, provincia de La Rioja. Revista del Instituto de Investigación Musicológica "Carlos Vega", 25, 141-193 Recuperado de https://core.ac.uk/download/pdf/129473915.pdf

"Quijano, A. (2000). Colonialidad del poder, eurocentrismo y América Latina. En E. Lander (Comp.). Colonialidad del saber: eurocentrismo y ciencias sociales. Perspectivas latinoamericanas (pp. 201-246). Buenos Aires: Consejo Latinoamericano de Ciencias Sociales; UNESCO.

"Racedo, J. (1996). El romancero y la copla: formas de oralidad entre dos mundos (EspañaArgentina). Sevilla: Virtudes Atero. Colección Nueva América № 2. La Rábida, Huelva: Universidad Internacional de Andalucía, Sede Iberoamericana de La Rábida / Universidad de Cádi; Universidad de Sevilla.

» Reyes, L. A. (2008). El pensamiento indígena en América. Buenos Aires: Biblos. 
»Rivera Andía, J. (2016). La vaquerita y su canto: una antropología de las emociones. Canciones rituales ganaderas en los Andes peruanos contemporáneos. Buenos Aires: Rumbo Sur; Ethnographica.

» Robin Azevedo, V. (2010). La petrificación de los antiguos en Chumbivilcas (Cuzco, Perú). De la wanka prehispánica al actual ramadero. Revista Española de Antropología Americana, 40(1), 219-238.

» Rozas Álvarez, J. (2007). El modo de pensar andino: Una interpretación de los rituales de Calca (tesis de maestría). Pontificia Universidad Católica del Perú. Recuperado de http://tesis.pucp.edu.pe/repositorio/bitstream/123456789/1409/1/ROZAS_ALVAREZ_JESUS_MODO.pdf

» Sulca, Eva (Ed.) (2016). Yanasiri. Coplas. Obras propias y recopilaciones. Córdoba: El Autor.

» Taboada de Pérez, M. S. (1995). Los cancioneros populares: ¿rescate o silenciamiento cultural? Aportes críticos a los estudios folklóricos sobre la copla campesina, en R. Kaliman (Ed.). Memorias de JALLA (pp. 90-105). Tucumán: Instituto de Historia y Pensamiento Argentinos, Facultad de Filosofía y Letras, Universidad Nacional de Tucumán.

» Tantaleán, H. y Leyva, M. Y. (2011). De la huanca a la estela: la formación de los asentamientos permanentes tempranos (1400 ANE-350 DNE) de la cuenca norte del Titicaca. Bulletin de l'Institut français d'études andines, 40(2), 259-287.

» Van Kessel, J. y Salas, P. (2002). Señas y señaleros de la madre tierra: agronomía andina. Quito; Iquique: Abya Yala; IECTA.

"Vega, C. (1965). Las canciones folklóricas argentinas. Buenos Aires: Editorial Instituto de Musicología, Subsecretaría de Cultura, Ministerio de Educación de la Nación.

»Viveiros de Castro, E. (2010). Metafísicas caníbales. Líneas de antropología postestructural. Buenos Aires: Katz.

» Viveiros de Castro, E. (2013). La mirada del jaguar. Introducción al perspectivismo amerindio. Entrevistas. Buenos Aires: Tinta Limón. 